\title{
Análise da Outorga Onerosa e Transferência do Direito de Construir em Goiânia - GO
}

Maria H. de Lima Moraes Murué ${ }^{1}$

Simone do Nascimento Costa ${ }^{2}$

Daniela Rosim ${ }^{3}$

Antonio Pasqualetto 4

\begin{abstract}
Resumo
O Estatuto da Cidade estabelece revisão do Plano Diretor dos municípios em 10 anos após sua última edição. Diante desta obrigação, é primordial para o planejamento analisar a aplicação e eficácia dos instrumentos Outorga Onerosa do Direito de Construir e Transferência do Direito de Construir no município de Goiânia, nos anos pós-publicação da LC 171/2007 - Plano Diretor. Os dados foram obtidos junto à Secretaria de Planejamento Urbano e Habitação e os resultados demonstraram amplo uso dos instrumentos, com necessidade de ajustes. $O$ objetivo foi verificar se a legislação está de acordo com o Estatuto da Cidade e o Plano Diretor em vigência, quais as consequências do uso dos instrumentos e as medidas necessárias na próxima revisão do Plano Diretor.
\end{abstract}

Palavras-chave: Estatuto da Cidade, Plano Diretor, Instrumentos Urbanísticos, Outorga Onerosa e Transferência do Direito de Construir.

\begin{abstract}
The City Statute of Brazil establishes that the Master Plan of the municipalities must be reviewed in 10 years after its last edition. In view of this obligation, is very important to analyze the application and effectiveness of instruments like Onerous Grant and Construction Right Transfer in the planning and control of land use and occupation in Goiânia city, after the publication of LC 171/2007 - Master Plan Directive. The data were obtained from the urban planning and housing secretariat from 2007 to 2017 and the results showed broad use of the instruments, however, they need adjustment. The main objective was to check if the relevant law about the issue is in agreement with the City Statute of Brazil, and the valid Master Plan Directive and what kind of intervention are needed for the next Master Plan revision.
\end{abstract}

Keywords: City Statute, Master Plan Directive, Urbanistic Instruments, Onerous Grant and the Construction Right Transfer.

\footnotetext{
${ }^{1}$ Mestre em Desenvolvimento e Planejamento Territorial. Professora da Pontifícia Universidade Católica de Goiás (PUC-GO). mheloisamm@gmail.com

${ }^{2}$ Mestre em Desenvolvimento e Planejamento Territorial. Professora da Pontifícia Universidade Católica de Goiás (PUC-GO).smncosta@gmail.com

${ }^{3}$ Doutora em Engenharia de Produção (USP). Professora da Pontifícia Universidade Católica de Goiás (PUC-GO). danielarosim@gmail.com

${ }^{4}$ Doutor em Fitotecnia (UFV). Professor do Programa de Pós-Graduação em Desenvolvimento e Planejamento Territorial e do Programa de Pós-Graduação em Engenharia de Produção e Sistemas, ambos da Pontifícia Universidade Católica de Goiás (PUC-GO). orcid.org/0000-0002-8639-6725. profpasqualetto@gmail.com
} 


\section{Introdução}

O direito urbanístico induziu mudanças introduzidas no cenário nacional efetivadas no Estatuto da Cidade (Lei no 10.257, de 10 de julho de 2001), quanto à visão de planejamento, gerando um novo desenho às cidades brasileiras. Uma novidade trazida pelo Estatuto é o fato de que todos os princípios e direitos estabelecidos na Constituição foram traduzidos em diversos instrumentos, mecanismos, processos e recursos nele apresentados (CARVALHO e ROSSBACH, 2010). O princípio da função social da propriedade passou a ter efeitos jurídicos concretos para o território, através dos Planos Diretores, das leis de zoneamento, de delimitação de áreas de urbanização prioritária, nas quais a retenção especulativa de imóveis urbanos deve ser combatida.

Cabe a cada município escolher, regulamentar e aplicar os instrumentos conforme a estratégia de desenvolvimento urbano desejada. Assim, determinada transformação pretendida depende da aplicação de um conjunto de ações de maneira coordenada e integrada no território. Desse modo, a regulamentação dos instrumentos deve ser feita dentro de uma estratégia de desenvolvimento urbano para sua efetiva aplicação e estar expressa no Plano Diretor. Colocado à disposição dos administradores municipais, essa nova ferramenta possibilita a atuação do poder público no sentido de reduzir as desigualdades além de permitir a organização das cidades.

Amparado nas determinações do Estatuto da Cidade, o município de Goiânia aprovou seu Plano Diretor em 2007, através da Lei Complementar no 171/2007. Com o objetivo de induzir o desenvolvimento urbano e a redistribuição à coletividade dos benefícios decorrentes do processo de urbanização apresentam em seus artigos 147, 150 e 157, 158 os instrumentos de outorga onerosa do direito de construir - OODC e de transferência do direito de construir - TDC.

Esses instrumentos foram posteriormente regulamentados através de leis específicas, quais sejam: Lei $n=8.618 / 2008$ que regulamenta a outorga onerosa e Lei $n=8.761 / 2009$ que regulamenta a transferência do direito de construir. Neste sentido, surgem algumas questões: 0 modo como Goiânia decidiu implantar esses instrumentos está de acordo com o que rege o Estatuto da Cidade? A utilização deles ocorreu conforme a intenção do planejamento? Portanto, a análise destes fatores pode orientar para correções necessárias, bem como novas estratégias de condução do planejamento da capital goiana.

Desta forma, objetivou-se analisar a emissão de Outorga Onerosa e de Transferência do Direito de Construir no Município de Goiânia com o enfoque na forma de como foram consolidadas as ações definidas pela legislação. 


\section{A utilização dos instrumentos urbanísticos de acordo com o Estatuto da Cidade, Plano Diretor e leis específicas}

Os instrumentos aqui tratados (Outorga Onerosa do Direito de Construir - OODC e Transferência do Direito de Construir - TDC) foram claramente apresentados no Estatuto da Cidade no inciso sobre os institutos jurídicos e políticos. Sua utilização permite intervenção social sobre o livre uso da propriedade privada (como desapropriação, tombamento, instituição de unidades de conservação, edificação ou utilização compulsórias e direito de preempção) e também a regularização fundiária das ocupações de interesse social (através da concessão de direito real de uso, concessão de uso especial para fins de moradia, usucapião especial de imóvel urbano, direito de superfície, legitimação da posse).

Embora sejam instrumentos distintos, guardam fundamentos comuns, baseados no entendimento do conceito de Solo Criado. Historicamente as bases teóricas desses instrumentos, no plano nacional, foram estabelecidas pela Carta de Embu, na década de 70, com a denominação de solo criado.

Solo criado será toda edificação acima do coeficiente único, quer envolva ocupação de espaço aéreo quer a de subsolo. (FUNDAÇÃO PREFEITO FARIA LIMA, 1977).

Ambos tratam de concessão emitida pelo município para criação de pisos artificiais acima da área do terreno, ou seja, acima do coeficiente de aproveitamento básico, dentro do limite máximo de densidade fixado pelo plano diretor, mediante contrapartida financeira. Nesse sentido, deixa de ser instrumento meramente arrecadador e passa a ser também forma de induzir o desenvolvimento urbano. Uma forma de fazer isso é limitar os estoques de área construída a serem disponibilizados para o mercado, oferecendo-os apenas naquelas áreas cujo crescimento deve ser incentivado.

De acordo com Furtado et al. (2012), no Caderno Técnico de Regulamentação e Implementação da OODC:

\footnotetext{
"Cabe delimitar a abrangência da OODC, que deve sempre estar contida entre dois critérios: o critério do Coeficiente de Aproveitamento - CA básico, que define a utilização autorizada para todos os terrenos urbanos sem o pagamento de contrapartida, e o limite máximo de aproveitamento, que define a maior utilização permitida para o terreno, a partir de critérios urbanísticos" (FURTADO et al., 2012, p13).

"A possibilidade do exercício de" direitos de construção adicionais ao definido pelo coeficiente de aproveitamento básico aumenta a densidade construtiva das áreas onde esses direitos adicionais sejam expressamente autorizados e, por isso, depende da capacidade de infraestrutura instalada ou prevista nessas áreas. Os limites máximos de aproveitamento dos terrenos urbanos devem ser sempre definidos a partir deste critério
} 
(Art. 28, § 3ㅇ), ou seja, somente as áreas adequadamente servidas de infraestrutura, ou onde esta infraestrutura esteja prevista, poderão ser passíveis da atribuição de direitos construtivos adicionais àquele definido pelo coeficiente de aproveitamento básico. Se esta condição prévia estiver atendida, então outros critérios e parâmetros urbanísticos podem ser acionados para a definição de limites máximos de edificabilidade para as diferentes zonas urbanas (FURTADO et al., 2012, p.16.)

Para o município de Goiânia, este instrumento já está estabelecido desde 1994, através do artigo 26 da Lei Complementar № 031/94:

Art. 26. A licença para construir além do coeficiente de aproveitamento não oneroso será concedida, observados os limites contidos das tabelas constantes do Anexo I, desta Lei, mediante pagamento pelo interessado de um valor monetário calculado de acordo com aplicação da seguinte tabela... (GOIÂNIA, 1994, p.09.)

\section{O Plano Diretor - LC № 171/2007 estabelece os princípios gerais para o assunto:}

Art. 146. O Município poderá outorgar onerosamente o exercício do direito de construir, mediante contrapartida financeira de preço público, bens, obras ou serviço, a serem prestadas pelo beneficiário, conforme disposições dos artigos 28, 29, 30 e 31 da Lei Federal no 10.257/01 - Estatuto da Cidade, de acordo com os critérios e procedimentos definidos nesta Lei e demais legislações pertinentes, quando for o caso.

Art. 147. As áreas passíveis de Outorga Onerosa do Direito de Construir são aquelas onde o direito de construir poderá ser exercido acima do permitido pela aplicação do Coeficiente de Aproveitamento Básico não oneroso, mediante contrapartida financeira. Art. 149. O impacto na infraestrutura, nos serviços públicos e no meio ambiente, resultante da concessão da Outorga Onerosa do Direito de Construir adicional, deverá ser monitorado permanentemente pelo órgão de planejamento municipal.

Art. 150. A Outorga Onerosa do Direito de Construir será concedida mediante o pagamento pelo beneficiário, de uma contrapartida financeira de preço público (GOIÂNIA, 2007, p.38).

Lei específica para o assunto é a de no 8.618/2008, que “regulamenta a concessão da Outorga Onerosa do Direito de Construir prevista na Lei Complementar n.o 171, de 29 de maio de 2007".

Art. 10 A Outorga Onerosa do Direito de Construir, para fins do disposto no art. 146 e seguintes da Lei Complementar n. 171/2007, consiste no direito de construir acima do Coeficiente de Aproveitamento Básico adotado pelo Município, mediante contrapartida a ser prestada pelo beneficiário.

$\S 1$ 10 A contrapartida de que trata o caput deste artigo, poderá ser prestados através de pagamento de preço público, bens, obras ou serviços, conforme disposto neste regulamento.

$\S 2$ 을 contrapartida poderá ser prestada diretamente pelo beneficiário ou por terceiro, por ele indicado, sendo que eventual inadimplência por parte do terceiro indicado, responderá por ele o beneficiário.

Art. 2o Para o cálculo da contrapartida financeira a ser oferecida quando da Outorga Onerosa do Direito de Construir, considera-se tabela de Preço Público o valor Referencial do Custo Unitário Básico de Construção (CUB) constante da Tabela elaborada pelo Sindicato da Indústria da Construção no Estado de Goiás - SINDUSCONGO. 
Art. 3ㅇ A contrapartida financeira do valor da outorga onerosa será efetuada em moeda corrente, podendo ser parcelada, em até 05 (cinco) vezes, paga trimestralmente, sendo o primeiro pagamento efetuado no ato de sua concessão.

Art. 40 Para o pagamento do valor da outorga onerosa, através de contrapartida em bens, obras ou serviços, o beneficiário poderá, após análise da conveniência pelo Órgão Municipal de Planejamento, celebrar Termo de Compromisso, como forma de transação, observando, para tanto, o disposto no art. 154 da Lei Complementar Municipal 171/2007. (GOIÂNIA, 2007, p.34,)

Conforme afirmado Oliveira e Carvalho (2002, p. 145), a construção acima do limite máximo permitido gera sobrecarga urbanística e ônus ao Poder Público, vez que é necessário fazer com que energia elétrica, saneamento, transporte público e áreas de lazer estejam igualmente disponíveis a todos os cidadãos e que as ruas e calçadas estejam transitáveis - sendo que a forma onerosa de adquirir esse direito de construir é um meio de equilibrar esse ônus com o particular. Seria "a aplicação do princípio da justa distribuição de ônus e encargos, assim como do direito a cidades sustentáveis".

Os autores relatam não ser a realização dessa paridade de ônus entre Poder Público e particular a principal vantagem dessa limitação ao direito de criar solo e sim que,

[...] a arrecadação que a Administração terá com a outorga onerosa possibilita a promoção do equilíbrio entre o crescimento e os serviços, aparelhando o Poder Público com meios econômicos de regularização fundiária, saneamento básico, programas habitacionais de direito à moradia. Viabiliza que aqueles efetivamente mais afortunados, se efetuarem o aproveitamento excessivo, sejam proporcionalmente onerados em favor dos menos favorecidos. Esta é a razão de o art. 31 da Lei destinar os recursos à correção das distorções do art. 26 (OLIVEIRA e CARVALHO, 2002, p. 147).

A TDC, por sua vez, consiste em um mecanismo pelo qual o poder público municipal faculta ao proprietário de imóvel urbano, a exercer em outro local, ou alienar, o direito de construir até um parâmetro básico definido por lei urbanística que não possa ser exercido no terreno de origem, total ou parcialmente, em face de interesses públicos legalmente definidos. Neste caso, autoriza-se o exercício do direito de construir em outro imóvel.

\footnotetext{
A transferência do direito de construir - TDC é uma faculdade dada ao proprietário de imóvel urbano, privado ou público, de exercer em outro local, ou alienar, mediante escritura pública, o direito de construir previsto no plano diretor, conjugando o interesse público com o particular sem despesas ao erário público. (GOIÂNIA, 2018, p.198.)
}

O pressuposto da transferência é que, embora se impeça o exercício do direito de construir em determinado imóvel, haja infraestrutura disponível no local de origem. Essa 
infraestrutura será então utilizada por outro imóvel, sem prejuízo para a qualidade de vida de seu entorno. Pode-se concluir, portanto, que o índice resultante não poderá exceder ao coeficiente de aproveitamento máximo previsto no plano diretor (PINTO, 2002).

Para Oliveira (2002), "a transferência do direito de construir poderá trazer forte impacto no mercado imobiliário, dando origem à propriedade virtual. Assim, o proprietário impedido de exercer seu direito no próprio imóvel, poderá construir em outro local, podendo os empreendedores imobiliários adquirir o direito de construir de proprietários que não possuam ou não queiram exercer o direito defluente de lei. Inaugura-se uma nova moeda de circulação no mercado e com valor econômico: o direito de construir".

A utilização da TDC encontra-se bem instruída no Estatuto da Cidade, que apresenta os critérios básicos de onde deverá ser aplicado instrumento:

1. Imóveis necessários para fins de implantação de equipamentos urbanos e comunitários;

2. Preservação, quando o imóvel for considerado de interesse histórico, ambiental, paisagístico, social ou cultural;

3. Servir a programas de regularização fundiária, urbanização de áreas ocupadas por população de baixa renda e habitação de interesse social.

Art. 35. Lei municipal, baseada no plano diretor, poderá autorizar o proprietário de imóvel urbano, privado ou público, a exercer em outro local, ou alienar, mediante escritura pública, o direito de construir previsto no plano diretor ou em legislação urbanística dele decorrente, quando o referido imóvel for considerado necessário para fins de:

I - implantação de equipamentos urbanos e comunitários;

II - preservação, quando o imóvel for considerado de interesse histórico, ambiental, paisagístico, social ou cultural; III - servir a programas de regularização fundiária, urbanização de áreas ocupadas por população de baixa renda e habitação de interesse social.

§ 1 A mesma faculdade poderá ser concedida ao proprietário que doar ao Poder Público seu imóvel, ou parte dele, para os fins previstos nos incisos I a III do caput.

§ 2ㅇ A lei municipal referida no caput estabelecerá as condições relativas à aplicação da transferência do direito de construir. (BRASIL, 2001, p.3)

No município de Goiânia este importante instrumento também já vinha sendo utilizado desde a Lei Complementar № 031/1994:

Art. 30. O Poder Executivo poderá autorizar o proprietário de imóvel considerado de interesse histórico ou cultural a exercer em outro local ou alienar, mediante escritura pública, o direito de construir igual a uma vez a área do respectivo terreno (GOIÂNIA, 1994, p.10). 

premissas do Estatuto da Cidade.

Art. 157. Fica autorizado ao proprietário de imóvel urbano, privado ou público, a exercer em outro local ou alienar, mediante escritura pública, o direito de construir quando o referido imóvel for considerado para fins de:

I - implantação de equipamentos urbanos e comunitários;

II - preservação, quando o imóvel for considerado de interesse histórico, ambiental, paisagístico, social ou cultural;

III - servir a programas de regularização fundiária, urbanização de áreas ocupadas por população de baixa renda e habitação de interesse social. (GOIÂNIA, 2007, p.39).

Direcionou também a localidade das áreas que poderão receber este potencial construtivo, inclusive delimitando sua transferência.

Art. 158. As áreas receptoras do potencial construtivo, objeto de Transferência do Direito de Construir, estarão localizadas na unidade territorial definida como Áreas Adensáveis, exclusivamente nas áreas pertencentes aos Eixos de Desenvolvimento e áreas objeto de aplicação de projeto diferenciado de urbanização, integrantes da Macrozona Construída.

$\S 1$ 을 Fica estabelecido como potencial máximo a ser transferido por unidade imobiliária, o equivalente a $25 \%$ da altura do edifício a ser implantado no imóvel receptor. (GOIÂNIA, 2007, p.39.)

A conceituação e aplicação do instrumento encontra-se definida na Lei no 8.761/09, a qual trata especificamente da TDC. Além desta lei, outras leis posteriores ampliaram tanto o potencial gerador de TDC quanto sua aplicação, a saber:

1 - A Lei Complementar № 181/08, em seu artigo 20, expande a aplicação de TDC para as faixas das áreas para ampliação do sistema viário e faculta sua aplicação na substituição da OODC além do já previsto como pagamento do potencial máximo de $25 \%$.

§ 10 Fica facultada a aplicação da Transferência do Direito de Construir - TDC, sobre a área objeto da complementação do sistema viário, nos termos de legislação própria. § 20 A TDC, de que trata o parágrafo anterior poderá ser utilizada em substituição ao instrumento da Outorga Onerosa do Direito de Construir - OODC, além do potencial máximo equivalente a $25 \%$ da altura do edifício conforme estabelecido no art. 158 da Lei Complementar no 171/2007. (GOIÂNIA, 2008, p.3).

Assim, com a LC № 181/2008 - Lei dos Vazios Urbanos, o instrumento passa a ser liberado com a finalidade de conseguir áreas para a implantação dos corredores (\$1ํ) e como "moeda" no pagamento de outorga onerosa (§2º). A Lei Complementar no 246/2013 (alteração da LC 171/2007 - Plano Diretor) faculta a aplicação de TDC nas áreas do PUAMA e excetua as 
áreas de desaceleração da aplicação de TDC.

Art. 133 (...)

§ 10 Fica garantido o disciplinamento especial, estabelecido em lei específica, para as áreas integrantes do Programa Urbano Ambiental Macambira Anicuns - PUAMA.

§ 20 Fica facultada a aplicação da TDC sobre as áreas integrantes do Programa Urbano Ambiental Macambira Anicuns - PUAMA, nos termos de legislação específica, exceto na Área de Desaceleração de Densidade. (GOIÂNIA, 2013, p.02).

Estabelecem-se dois tipos de "coeficientes" previstos na nossa legislação: o coeficiente de aproveitamento básico não oneroso, equivalente ao potencial dado pela unidade imobiliária do imóvel em qualquer local da cidade, e o coeficiente de aproveitamento máximo, alcançado pelo instrumento da OODC em conjunto com a TDC. Para a avaliação da emissão e aplicação da OODC foi levantada a quantidade total de pareceres emitidos desde o ano de 2008 (ano de publicação da lei específica de OODC) até o ano de 2016. Identifica-se que os dois instrumentos são diferentes em seu modo de liberação, mas constituem um único princípio: o de permitir alterações no solo urbano, para que a cidade possa crescer e se adaptar às constantes transformações de maneira organizada e planejada.

Para a avaliação da aplicação dos instrumentos no município de Goiânia, foram utilizados dados da Secretaria Municipal de Planejamento Urbano e Habitação, através do Fundo Municipal de Desenvolvimento Urbano - FMDU, responsável pela emissão do documento da outorga onerosa e do Comitê de Uso e Ocupação do Solo, responsável pela emissão dos pareceres de TDC. Para a avaliação do TDC foram levantados os pareceres e "créditos" emitidos desde a aprovação da lei específica. Identificadas as áreas objeto de doação (aquelas impedidas de alcançar todo o seu potencial), e os locais de interesse do mercado imobiliário para uso do instrumento, bairros preferenciais.

Os dados levantados foram processados em um sistema denominado "Tableau", desenvolvido especialmente pela Prefeitura para tratamentos de dados municipais e apresentados na forma de figuras.

\section{Outorga Onerosa de Direito de Construir (OODC)}

Para a avaliação dos dados levantados, considerações são importantes quanto à característica de utilização da OODC no município de Goiânia: a) Até 2010, a concessão de OODC 
se deu para projetos protocolados para análise à luz da Lei Complementar no 031/1994, sendo sua utilização não direcionada aos eixos de desenvolvimento e às unidades territoriais previstas pelo atual Plano Diretor; b) No período de 2010 a 2016, sua aplicação foi direcionada principalmente às áreas adensáveis propostas pelo Plano Diretor, sendo negociados 898.444,16 $\mathrm{m}^{2}$ de área junto ao FMDU, segundo dados extraídos da Secretaria Municipal de Planejamento Urbano e Habitação - SEPLANH, através do sistema Tableau. A figura 1 demonstra a relação de OODC concedidas no período de 2007 a 2016.

Figura 1 - Licenças de outorga onerosa de direito de construir concedidas/ano em Goiânia, GO.



Fonte dos dados: Gerência Fundo Municipal de Desenvolvimento Urbano SEPLANH, 2017.

Cabe ressaltar que tais OODC referem-se às concessões, cujas negociações para quitação não foram mediantes TDC. O período de maior emissão de OODC foram os anos de 2009 a 2012, período em que o instrumento se consolida. Após 2012 houve decréscimo considerável na emissão de outorga onerosa, fato ocorrido em função da publicação da LC no 246/2013, que permitiu o pagamento de outorga onerosa com títulos adquiridos através de TDC.

Analisando as liberações de OODC feitas pelo município, houve diluição de sua aplicação dentro da área urbana, sem que ela gerasse adensamentos significativos. Os locais de maior utilização são principalmente aqueles situados em áreas adensáveis por direcionamento do próprio Plano Diretor, principalmente os Setores Bueno, Marista e Jardim América.

\section{A Transferência do Direito de Construir - TDC}


Os dados foram tratados tendo como base as seguintes características:

a) Tipo de utilização da área doada: com qual finalidade a área foi recebida pelo município. De acordo com a legislação vigente no município de Goiânia, as áreas aptas a receberem a troca de seu potencial por índice de TDC são aquelas destinadas à ampliação do sistema viário, ao Parque Urbano Ambiental Macambira Anicuns-PUAMA e outras consideradas de interesse público pela gestão municipal (identificada nas tabelas como "doações diversas");

b) Tipo de uso do instrumento na construção: como os receptores de TDC estão utilizando o crédito em obras edilícias.

c) Locais de utilização do instrumento: quais os bairros foram os maiores receptores do instrumento.

A figura 2 traz o tipo de utilização da área com TDC em Goiânia, GO. Foram emitidos até o mês de junho/2017 pareceres transferindo o direito de construir de uma área para outra.

Figura 2. Tipo de utilização da área doada em Goiânia, GO

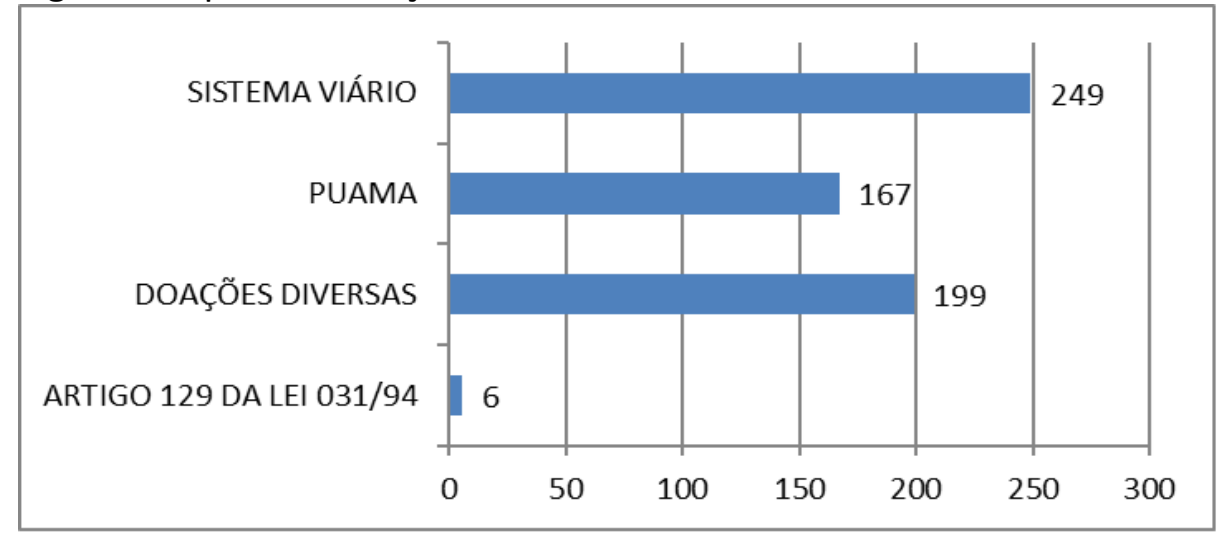

Fonte dos dados: Adaptado de Comitê de Uso e Ocupação do Solo - SEPLANH, 2017.

Verifica-se que o maior percentual de áreas recebidas se destina a melhorias do sistema viário, indo de encontro ao que define a LC 171/2007-Plano Diretor, no que se refere à necessidade de implantação dos eixos de desenvolvimento:

Art. 82. Para efeito de implementação do modelo espacial e visando promover um maior ordenamento das funções urbanas, integrando o uso do solo ao sistema de mobilidade urbana, ficam instituídos os Eixos de Desenvolvimento, apoiados na rede estrutural de transporte coletivo:

I - Eixos de Desenvolvimento Exclusivos, referentes aos eixos de transporte coletivo com corredores exclusivos, compreendendo: o Corredor Anhanguera; o Corredor Goiás; o Corredor Mutirão; o Corredor T-9; o Corredor T-7 e o Corredor Leste - Oeste;

II - Eixos de Desenvolvimento Preferenciais, referentes aos eixos de transporte coletivo com corredores preferenciais, em sua grande maioria situados a sudoeste da cidade, e que estão destinados preferencialmente à política habitacional de baixa renda, por meio da instituição das Áreas de Interesse Social, compreendendo: o Corredor 20 - Rodovia 
GO - 070; o Corredor 19 - GYN 24; o Corredor 17 - Av. Pedro Ludovico; o Corredor T-9 - Tramo Setor Garavelo/GO-040; Corredor Anhanguera - Tramo Vila Pedroso; Corredor Goiás Norte; e, o Corredor Goiânia II/Campus UFG. (GOIÂNIA, 2007, p.29)

Em análise às liberações de TDC emitidas pelo município, é possível perceber que a aplicação do instrumento em Goiânia acontece em duas fases distintas. Uma até 2009, onde sua função se restringia ao que rege o Estatuto da Cidade e outra de 2009 até os dias atuais, onde a aplicação do instrumento foi direcionada para alguns fins específicos, descritos a seguir:

a) Era de interesse do município a aquisição de faixas de áreas para complementação do sistema viário junto aos corredores exclusivos e preferenciais, para que fossem efetivados os eixos de desenvolvimento propostos pelo Plano Diretor.

b) Era também de interesse do município a implantação do Parque Urbano Ambiental Macambira Anicuns - PUAMA, parque linear com $24 \mathrm{~km}$ de extensão, e para que fosse possível sua realização seria necessária à desapropriação de diversas áreas ao longo do córrego Macambira e ribeirão Anicuns.

Na figura 3, evidencia-se que o ano de 2014 predominou o uso do instrumento TDC Transferência do direito de construir em Goiânia.

Figura 3. Quantitativo de TDC para substituição de OODC em Goiânia, GO, 2007 a 2018.



Fonte dos dados: Adaptado de Comitê de Uso e Ocupação do Solo - SEPLANH, 2017.

Foram identificadas pelo mercado imobiliário potencialidades para utilização desta lei, não previstas quando da elaboração da mesma. Uma primeira refere-se às áreas doadas como reserva do sistema viário para os corredores estavam localizadas em áreas afastadas do centro, onde a implantação deles ainda demanda tempo. Há áreas em que ainda não há nem a via aberta. Isso gerou a concentração de metros quadrados em TDC no mercado. 
A segunda trata da liberação para utilização do instrumento como substituição ao pagamento da outorga onerosa para o município abriu o mercado para a venda desses "créditos" em TDC a preço menor que o instrumento de outorga onerosa gerado pelo município, causando concorrência com o próprio município. Com grande quantidade de TDC no mercado, passou a ser mais vantajosa a aquisição de TDC que a de outorga onerosa, mesmo sendo seu pagamento trimestral.

\section{A utilização em conjunto dos dois instrumentos}

O instrumento de gestão urbanística TDC se distingue do instrumento OODC no trâmite realizado pelo recurso oriundo da sobrevalorização de lotes de terreno beneficiados pelo aumento de potencial construtivo. Na Outorga Onerosa, o recurso é destinado a obras e serviços públicos ainda não especificados, via Fundos Municipais de Desenvolvimento Urbano, componentes dos Orçamentos Municipais.

Na Transferência, o recurso é destinado a obras e serviços de interesse públicos previamente definidos, por intermédio dos próprios agentes privados que atuam no mercado imobiliário. Vista desde as zonas de destino, a Transferência do Direito de Construir não é, pois, senão uma espécie de Outorga Onerosa "terceirizada".

Como pôde ser percebida, a legislação de Goiânia permite o uso em conjunto dos instrumentos de OODC e TDC. Enquanto complementares, se apoiam como auxiliares no equilíbrio do planejamento urbano. Entretanto, a partir da LC no 246/2013, que permitiu o pagamento de outorga através de títulos de TDC, os dois instrumentos passam a ser "concorrentes". Dessa forma, deverão ser estabelecidas ações que visam, além de preservar a utilização do instrumento, melhorar sua aplicabilidade. Uma primeira proposta de alteração consiste na forma de utilização da TDC restringindo a substituição total da OODC pela TDC, prevista na Lei Complementar no 181/ 2008 - Vazios Urbanos.

Outra forma de utilização visa incentivar o uso misto nas edificações e a utilização de fachadas ativas situadas em áreas influência dos Eixos de Desenvolvimento, bem como na Área de Desaceleração de Densidades e nos Projetos Diferenciados de Urbanização. Fachada ativa corresponde à ocupação da fachada localizada no alinhamento de passeios públicos por uso não residencial com acesso aberto à população e abertura para o logradouro como forma de incentivo, as atividades econômicas situadas no pavimento térreo dos edifícios de uso misto não terão suas áreas computadas para fins de cálculo da Outorga Onerosa do Direito de Construir 
(OODC). Para tal, a fachada ativa deve apresentar a ocupação da extensão horizontal da fachada por uso não residencial com acesso direto e abertura para o logradouro público, a fim de evitar a formação de planos fechados na interface entre as construções e o logradouro lindeiro.

Outra importante alteração a ser feita trata da saturação dos serviços e densidades planejadas para determinada região com previsão de suspensão da aplicação da OODC até que sejam definidas medidas que possam congelar a situação ou revertê-la, objetivando reestruturar a área saturada. Outra proposta adotada neste cenário de alteração da aplicação da TDC será reduzir o potencial construtivo daquelas originárias de aquisição de faixas de áreas para a complementação do sistema viário junto aos corredores exclusivos e preferenciais.

Por fim, importante avaliar que não seja mais permitida a aplicação da TDC na unidade territorial identificada como Área de Desaceleração de Densidade (ADD) e na Área de Ocupação Sustentável (AOS), uma vez que para essas unidades territoriais não haverá incentivo de sobredensidade.

Tais medidas buscam a redução de emissão de TDC pelo Município, com o objetivo de resgatar a utilidade da TDC, possibilitando, implementação mais adequada da política urbana. Cabe ressaltar, porém, que há situações que não serão retratadas na revisão do Plano Diretor, mas sim em lei específica sobre Transferência do Direito de Construir.

\section{Considerações finais}

São importantes ao município de Goiânia a utilização dos instrumentos de outorga onerosa (OODC) e transferência do direito de construir (TDC). A OODC tem se mostrado bastante eficiente e explorada pelo mercado imobiliário e pela construção civil da capital, haja vista a quantidade de unidades habitacionais viabilizadas através de sua aplicação, principalmente aquelas direcionadas para as áreas adensáveis da cidade distribuídas ao longo dos eixos de desenvolvimento, corredores viários, conforme preconizado pelo Plano Diretor.

A TDC também tem se mostrado importante aliado para que sejam viabilizados projetos de planejamento, em função da amplitude de locais em que pode ser aplicada. Ajustes são necessários e urgentes. A revisão do atual Plano Diretor do Município prevê alterações significativas na aplicação dos instrumentos.

\section{Referências}


Barros, A. M. F. B.; Carvalho, C. S.; Montandon D. T. O Estatuto da Cidade Comentado. São Paulo: Ministério das Cidades: Aliança das Cidades. 2010, 120p. Disponível em:

http://www.cidades.gov.br/images/stories/ArquivosSNPU/Biblioteca/PlanelamentoUrbano/Est atutoComentado_Portugues.pdf. Acesso em: 08 nov. 2018.

Brasil. Constituição da República Federativa do Brasil. Brasília. 1988

Brasil. Lei no 10.257, de 10 de julho de 2001. Estatuto da Cidade. In: Diário Oficial da União no 133, p. 1 a 5, Brasília. 2001.

Carvalho, C. S., Rossbach, A. C. Aliança das Cidades. O Estatuto da Cidade Comentado. São Paulo. Ministério das Cidades. 2010.

Fundação Prefeito Faria Lima. Solo Criado/Carta do Embu, 11 de dezembro de 1977.

Furtado, F.; Biasotto, R. e Maleronka, C. Outorga Onerosa do Direito de Construir. (1 vol., 68p.) Ministério das cidades: Coleção Cadernos Técnicos de Regulamentação e Implementação de Instrumentos do Estatuto da Cidade. Brasília. 2012

Goiânia. Lei Complementar no 031 de 29 de dezembro de 1994. Lei de Zoneamento de Goiânia. Diário Oficial do Município de Goiânia, n. 1320 de 29 de dezembro de 1994.

Goiânia. Lei Complementar n 171, de 29 de maio de 2007. Plano Diretor de Goiânia. Diário Oficial do Município de Goiânia, n. 4147 de 26 de junho de 2007.

Goiânia. Lei Complementar $n^{\circ}$ 246, de 29 de abril de 2013. Altera a Lei Complementar no 171 que dispõe sobre o Plano Diretor. Diário Oficial do Município de Goiânia, n. 5582 de 30 de abril de 2013.

Goiânia. Lei no 8.618, de 09 de janeiro de 2008. Regulamenta a concessão da Outorga Onerosa do Direito de Construir. Diário Oficial do Município de Goiânia, n. 4286 de 17 de janeiro de 2008.

Goiânia. Lei no 8.761, de 19 de janeiro de 2009. Regulamenta a concessão da Transferência do Direito de Construir. Diário Oficial do Município de Goiânia, n. 4536 de 21 de janeiro de 2009.

Goiânia. Prefeitura Municipal de Goiânia. Eixo de Ordenamento Territorial: Diagnóstico.

Secretaria Municipal de Planejamento Urbano e Habitação - SEPLANH. Comissão Executiva do Plano Diretor. Goiânia. 2018. 382p.

Oliveira, A. P. de; Carvalho, P. C. P. Estatuto da Cidade: anotações à Lei 10.257, de 10.07.2001. Curitiba: Editora Juruá. 2002.

Oliveira, R. F. de. Comentários ao Estatuto da Cidade. São Paulo: Editora Revista dos Tribunais. $2002,128 p$

Pinto, V. C. Avaliando o estatuto da cidade. Porto Alegre: Evangraf, II Congresso Brasileiro de Direito Urbanístico. 2002.

Santin, J. R., Marangon, E. G. de. O estatuto da cidade e os instrumentos de política urbana para proteção do patrimônio histórico: outorga onerosa e transferência do direito de construir. São Paulo 2008. Disponível em http://www.scielo.br/scielo.php?script=sci_arttext\&pid=S010190742008000200006\&lng=en\&nrm=iso\&tlng=pt a. Acesso em: 22 set. 2017. 